\title{
Routine low-dose calcium supplementation after thyroidectomy does not reduce the rate of symptomatic hypocalcemia: a prospective randomized trial
}

\author{
Jun Woo Lee ${ }^{1,2}$, Jong-Kyu Kim ${ }^{1,2}$, Hyungju Kwon ${ }^{1,2}$, Woosung Lim ${ }^{1,2}$, Byung-In Moon ${ }^{1,2}$, Nam Sun Paik ${ }^{1,2}$ \\ ${ }^{1}$ Department of Surgery, Ewha Womans University Medical Center, Seoul, Korea \\ ${ }^{2}$ Breast and Thyroid Cancer Center, Ewha Womans University Cancer Hospital, Seoul, Korea
}

\begin{abstract}
Purpose: Routine supplementation of high-dose calcium significantly decreased the risk of postoperative symptomatic hypocalcemia after thyroidectomy. However, there is an ongoing debate about whether the same results can be achieved with low-dose calcium supplementation.

Methods: Patients ( $\mathrm{n}=138$ ) who underwent total thyroidectomy for thyroid cancer were 1:1 randomly assigned to receive oral supplements of $1,500 \mathrm{mg} /$ day elemental calcium and 1,000 IU/day cholecalciferol for 2 weeks or no supplementation. Primary objective was to compare the incidence of symptomatic hypocalcemia for 3 days after total thyroidectomy. Secondary objective was to find the predictors for postoperative hypocalcemia in patients with thyroid cancer.

Results: Sixty-five patients in the calcium group and 69 patients in the control group were finally analyzed. The incidence of symptomatic hypocalcemia showed no difference between the calcium and control group $(32.3 \%$ vs. 21.7\%, $P=0.168)$. The total dosage of intravenous calcium $(593.4 \pm 267.1 \mathrm{mg}$ vs. $731.6 \pm 622.7 \mathrm{mg}, P=0.430$ ) administered to patients with symptomatic hypocalcemia was also comparable between groups. In a multivariate analysis, parathyroid hormone level of $13 \mathrm{pg} / \mathrm{mL}$ at postoperative day 1 was only predictive for symptomatic hypocalcemia, and its incidence was 20.9 times $195 \%$ confidence interval, 6.8-64.5) higher in patients with parathyroid hormone $<13 \mathrm{pg} / \mathrm{mL}$. Other factors did not predict the development of hypocalcemia, including clinicopathological features and routine supplementation of low-dose calcium. Conclusion: Routine low-dose calcium supplementation did not reduce the risk of postoperative hypocalcemia. Patients who may benefit from calcium supplementation should be carefully selected.

[Ann Surg Treat Res 2019;96(4):177-184]
\end{abstract}

Key Words: Calcium, Thyroidectomy, Hypocalcemia, Hypoparathyroidism, Thyroid neoplasms

\section{INTRODUCTION}

Thyroid cancer is now the most common cancer in Korea, and its incidence has increased over the past 20 years [1]. The age-standardized incidence rate per 100,000 men and women has increased from 2.1 and 10.4 in 1999 to 24.0 and 96.6 in 2013, respectively [1]. Because surgery is the mainstay of treatment for thyroid cancer, there is a growing interest in reducing postoperative complications [2]. Postoperative transient hypocalcemia is the most frequent complication after thyroidectomy, with a reported incidence of $1.6 \%-50 \%$ [3-5]. The causes of postoperative hypocalcemia include unintentional injury to the parathyroid glands, inexperience of the surgeon, retrosternal goiter, hyperthyroidism, and extent of neck dissection [6]. Postoperative hypocalcemia is associated with longer hospital stay, the need for extra blood tests, and
Received September 27, 2018, Revised November 14, 2018,

Accepted December 11, 2018

Corresponding Author: Hyungju Kwon

Department of Surgery, Ewha Womans University Medical Center, 1071

Anyangcheon-ro, Yangcheon-gu, Seoul 07985, Korea

Tel: +82-2-2650-5273, Fax: +82-2-2644-7984

E-mail: hkwon@ewha.ac.kr

ORCID code: https://orcid.org/0000-0003-4979-8749
Copyright (C) 2019, the Korean Surgical Society

(c) Annals of Surgical Treatment and Research is an Open Access Journal. All articles are distributed under the terms of the Creative Commons Attribution NonCommercial License (http://creativecommons.org/licenses/by-nc/4.0/) which permits unrestricted non-commercial use, distribution, and reproduction in any medium, provided the original work is properly cited. 
increased medical costs [7,8].

Several studies investigated preventive measures to reduce postoperative hypocalcemia, including postoperative supplementation of calcium, vitamin D, and/or thiazide diuretics [9]. Of these measures, routine calcium and vitamin D supplementation has been most widely used, especially in outpatient thyroidectomy patients [10]. However, whether routine calcium and vitamin D supplementation can decrease the risk of symptomatic hypocalcemia after thyroidectomy remains undetermined. Some studies reported that routine calcium and/or vitamin D supplementation was effective in preventing postoperative symptomatic and biochemical hypocalcemia [11-13], whereas other studies reported no benefits $[14,15]$. These inconsistent results were probably due to the different doses of supplemented calcium; a higher dose of elemental calcium supplement (2,000-3,000 mg/day) usually resulted in a reduced risk of hypocalcemia, whereas a lower dose $(600 \mathrm{mg} /$ day) showed no effect.

Although calcium supplementation in higher doses significantly decreased postoperative hypocalcemia, higher doses can have adverse effects including nausea, reduced appetite, constipation, and risk of hypercalcemia [16]. Delbridge [17] indicated that $12 \%$ of patients receiving routine calcium supplements required readmission due to hypercalcemia. Additional laboratory assessments to prevent hypercalcemia can be burdensome and incur extra medical costs. High calcium doses or hypercalcemia may further suppress normal parathyroid hormone (PTH) secretion and prolong suppression of the parathyroid glands [14]. Stimulated by these observations, we investigated the use of low-dose calcium supplementation for preventing postoperative hypocalcemia.

We hypothesized that low-dose calcium $(1,500 \mathrm{mg} /$ day elemental calcium) would reduce the rate of symptomatic hypocalcemia in patients with thyroid cancer after total thyroidectomy. The present study investigated the effect of routine calcium supplementation and aimed to find the predictors for postoperative hypocalcemia in patients with thyroid cancer.

\section{METHODS}

\section{Patient selection}

Eligible patients had a diagnosis of papillary thyroid carcinoma and underwent bilateral total thyroidectomy. Patients with suspicious lymph node on ultrasound underwent therapeutic central lymph node (LN) dissection. Patients were 20 years of age or older were enrolled. Eligibility also included acceptable renal and hepatic function and adequate thyroid function. Patients underwent modified radical neck dissection or combined resection of adjacent organ including trachea were excluded. Patients were also excluded if parathyroid adenoma was found during total thyroidectomy; history of neck surgery or radiation therapy; or prior use of calcium and/or vitamin D.

\section{Study design}

This study was a prospective randomized nonblinded controlled trial conducted in Korea (ClinicalTirals.gov identifier: NCT03484416). The protocol was approved by the Institutional Review Board of Ewha Womans University Mokdong Hospital (approval number: 2017-09-055), and written informed consent was obtained from each participant. Enrolled participants were randomly assigned in a 1:1 ratio to receive calcium and vitamin D (routine calcium group) or no supplementation (control group). Random assignment was performed after completion of bilateral total thyroidectomy, using a computer-generated permuted blocks (size 4).

\section{Study end points}

The primary endpoint of the study was to investigate the effect of routine calcium and vitamin D supplementation, as assessed by the incidence of symptomatic hypocalcemia for 3 days after total thyroidectomy. Symptomatic hypocalcemia was defined as an ionized calcium concentration below $4.6 \mathrm{mg} / \mathrm{dL}$ (normal range, $4.6-5.4 \mathrm{mg} / \mathrm{dL}$ ) associated with hypocalcemic symptoms [18]. Hypocalcemic symptoms were defined as perioral numbness, tingling sense or paresthesia at extermities, or muscle cramp and assessed by single endocrine surgeon (HK). Secondary objective was to find the predictors for postoperative hypocalcemia in patients with thyroid cancer.

\section{Procedures}

Patients in the routine calcium group received oral supplements of $1,500 \mathrm{mg} /$ day elemental calcium and 1,000 IU/day cholecalciferol for 2 weeks, beginning on the first postoperative day (POD) to the 14th POD, whereas patients in the control group received no supplementation. Serum concentrations of PTH and ionized calcium were measured 1 and 14 days postoperatively. If symptomatic hypocalcemia developed, patients in both groups received $2.0 \mathrm{~g}$ of intravenous calcium, followed by oral supplementation with $3,000-4,000 \mathrm{mg} / \mathrm{day}$ elemental calcium and 1,000-2,000 IU/day cholecalciferol up to the 14th POD. If hypocalcemic symptoms were persistent or worsening 2 hours after intravenous calcium administration, patients were administered another intravenous calcium supplementation.

All patients were followed at intervals of 2 weeks, 3 months, and then 6 months. Follow-up tests included clinical evaluation for hypocalcemia, and a thyroid function test. Hypocalcemia was considered permanent in patients who required calcium supplementation for longer than 6 months after thyroidectomy. 


\section{Statistical analysis}

The benchmark data for power calculation was adapted from the meta-analysis by Alhefdhi et al. [19], which demonstrated that the incidence of postoperative hypocalcemia were $6.8 \%$ versus $25.9 \%$ for calcium and vitamin D versus no intervention. Assuming the risk of symptomatic hypocalcemia in the routine calcium group equal to $6.8 \%$ and in the control group equal to $25.9 \%$, with a 2 -tailed alpha of $5 \%$ and $80 \%$ power, 116 patients were required for 1:1 randomization without continuity correction. Considering 20\% dropout rate, we planned to enroll 138 patients.

Statistical tests were performed using IBM SPSS Statistics ver. 22.0 (IBM Co., Armonk, NY, USA). Continuous variables were compared using Student t-tests and Mann-Whitney U-tests, and categorical variables were compared using chi-square tests. Bivariate logistic regression model was used to evaluate the relationship between PTH level and the development of hypocalcemia. Recursive partitioning and regression trees (RPART) classification algorithm in R 3.4.0 (R Development Core Team, Vienna, Austria) was used to identify the optimal cutoff value for PTH level. Two-sided P-values $\leq 0.05$ were considered statistically significant.

\section{RESULTS}

From March 2016 to May 2017, 142 patients with thyroid cancer underwent total thyroidectomy in our institution (Fig. 1). Three patients refused the study and 1 patient with concomitant parathyroid adenoma were excluded. The remaining 138 patients were randomly 1:1 assigned after total thyroidectomy, whether to receive or not to receive routine calcium supplementation. After randomization, 4 patients in the calcium group with incomplete perioperative data $(\mathrm{n}=$ 2), consent withdrawal $(n=1)$, or lost to follow-up $(n=1)$ were further excluded from analysis. Sixty-five patients in the calcium group and 69 patients in the control group were included for the final analysis.

\section{Effect of low-dose calcium and vitamin D supplementation}

The clinicopathologic characteristics of the 134 included patients are shown in Table 1. The calcium group and control group were well-matched for sex, age, the number of inadvertently resected or autotransplanted parathyroid glands, and American Joint Committee on Cancer TNM stage. The incidence of symptomatic hypocalcemia was higher in the calcium group than in the control group $(32.3 \%$ vs. $21.7 \%, \mathrm{P}=$ 0.168 ), although the difference was not statistically significant. On POD 1, serum concentrations of ionized calcium $(4.2 \pm 0.4$ $\mathrm{mg} / \mathrm{dL}$ vs. $4.3 \pm 0.3 \mathrm{mg} / \mathrm{dL}, \mathrm{P}=0.100)$ and PTH $(20.2 \pm 11.6 \mathrm{pg} /$ $\mathrm{mL}$ vs. $21.6 \pm 13.1 \mathrm{pg} / \mathrm{mL}, \mathrm{P}=0.524$ ) were comparable in the calcium and control groups. The increase in PTH level from POD 1 to 14 was also similar in both groups $(6.8 \pm 10.3 \mathrm{pg} / \mathrm{mL}$ vs. $8.6 \pm$ $14.2 \mathrm{pg} / \mathrm{mL}, \mathrm{P}=0.410$ ). The risk of permanent hypocalcemia was comparable between the groups $(0.0 \%$ vs. $1.4 \%, \mathrm{P}=0.330)$.

Twenty-one patients $(32.3 \%)$ in the calcium group and $15(21.7 \%)$ in the control group experienced symptomatic hypocalcemia. The total dosage of intravenous calcium $(593.4$ $\pm 267.1 \mathrm{mg} v$ vs. $731.6 \pm 622.7 \mathrm{mg}, \mathrm{P}=0.430$ ) needed in patients with symptomatic hypocalcemia were comparable between the 2 groups. The majority of patients experienced symptomatic hypocalcemia within 24 hours ( $71.4 \%$ vs. 66.7\%, $P=0.760$ ) in both groups. Only 1 patient in the control group developed hypocalcemic symptom after 48 hours. No patients experienced hypercalcemia in either group.

\section{Predictors for postoperative hypocalcemia}

Using the RPART classification algorithm, POD 1 PTH level

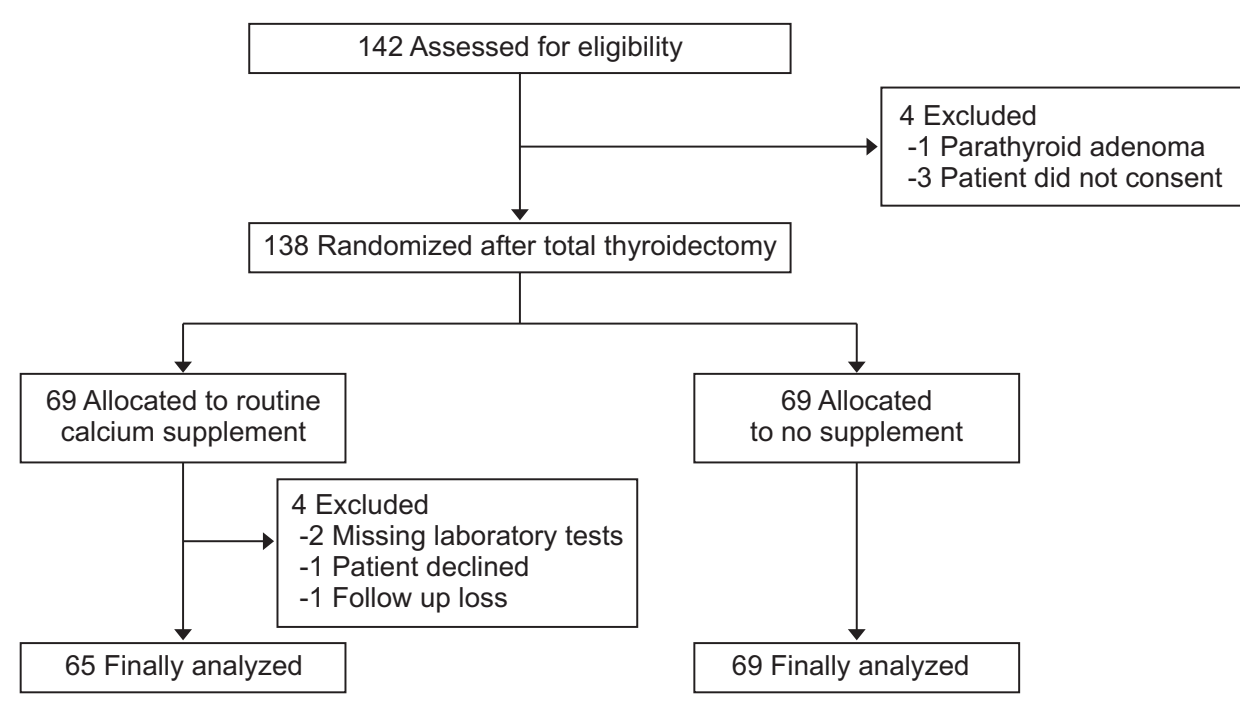

Fig. 1. Consolidated standards of reporting clinical trials flow chart. 
Table 1. Clinicopathological features of the routine calcium and control groups

\begin{tabular}{|c|c|c|c|}
\hline Characteristic & $\begin{array}{l}\text { Calcium supplement group } \\
\qquad(\mathrm{n}=65)\end{array}$ & $\begin{array}{l}\text { Control group } \\
\qquad(\mathrm{n}=69)\end{array}$ & P-value \\
\hline Female sex & $54(83.1)$ & $63(91.3)$ & 0.153 \\
\hline Age $(y r)$ & $49.1 \pm 10.9$ & $51.2 \pm 12.8$ & 0.314 \\
\hline Combined central LN dissection & $50(76.9)$ & $44(63.8)$ & 0.096 \\
\hline Inadvertent PTG excision & & & 0.625 \\
\hline O PTG & $58(89.2)$ & $60(87.0)$ & \\
\hline 1 PTG & $5(7.7)$ & $8(11.6)$ & \\
\hline 2 PTGs & $2(3.1)$ & $1(1.4)$ & \\
\hline PTG autotransplantation & $2(3.1)$ & $2(2.9)$ & 0.952 \\
\hline \multicolumn{4}{|l|}{ Tumor characteristics } \\
\hline Tumor size $(\mathrm{cm})$ & $1.3 \pm 1.1$ & $1.1 \pm 0.6$ & 0.401 \\
\hline Minimal extrathyroidal extension & $42(64.6)$ & $41(59.4)$ & 0.536 \\
\hline $\mathrm{LN}$ metastasis & $25(38.5)$ & $28(40.6)$ & 0.802 \\
\hline AJCC 7th classification & & & 0.094 \\
\hline T1N0 & $6(9.2)$ & $15(21.7)$ & \\
\hline T1N1a & $7(10.8)$ & $10(14.5)$ & \\
\hline $\mathrm{T} 1 \mathrm{Nx}$ & $8(12.3)$ & $3(4.3)$ & \\
\hline T2N1a & $1(1.5)$ & $0(0)$ & \\
\hline T3N0 & $17(26.2)$ & $20(29.0)$ & \\
\hline T3N1a & $17(26.2)$ & $18(26.1)$ & \\
\hline $\mathrm{T} 3 \mathrm{Nx}$ & $9(13.8)$ & $3(4.3)$ & \\
\hline \multicolumn{4}{|l|}{ Laboratory findings } \\
\hline Preoperative vitamin D (pg/mL) & $30.2 \pm 10.1$ & $29.7 \pm 10.3$ & 0.580 \\
\hline Preoperative PTH (pg/mL) & $20.2 \pm 11.6$ & $21.6 \pm 13.1$ & 0.524 \\
\hline POD 1 PTH $(p g / m L)$ & $20.2 \pm 11.6$ & $21.6 \pm 13.1$ & 0.524 \\
\hline POD 1 ionized calcium (mg/dL) & $4.2 \pm 0.4$ & $4.3 \pm 0.3$ & 0.100 \\
\hline POD 14 PTH $(p g / m L)$ & $27.0 \pm 12.5$ & $31.6 \pm 13.0$ & 0.039 \\
\hline POD 14 ionized calcium (mg/dL) & $4.8 \pm 0.4$ & $4.8 \pm 0.4$ & 0.461 \\
\hline Increase in PTH from POD 1 to $14(\mathrm{pg} / \mathrm{mL})$ & $6.8 \pm 10.3$ & $8.6 \pm 14.2$ & 0.093 \\
\hline Symptomatic hypocalcemia & $21(32.3)$ & $15(21.7)$ & 0.168 \\
\hline IV calcium dosage (mg) & $593.4 \pm 267.1$ & $731.6 \pm 622.7$ & 0.430 \\
\hline Occurred within $24 \mathrm{hr}$ & $15 / 21(71.4)$ & $10 / 15(66.7)$ & 0.760 \\
\hline Permanent hypocalcemia & $0(0)$ & $1(1.4)$ & 0.330 \\
\hline
\end{tabular}

Values are presented as number (\%) or mean \pm standard deviation.

LN, lymph node; PTG, parathyroid gland; AJCC, American Joint Committee on Cancer; POD, postoperative day; PTH, parathyroid hormone; IV, intravenous.

of $13 \mathrm{pg} / \mathrm{mL}$ was determined as the cutoff value for developing symptomatic hypocalcemia [20]. Forty-one patients (30.6\%) showed POD 1 PTH $<13 \mathrm{pg} / \mathrm{mL}$, whereas POD 1 PTH level was greater than or equal to 13 in 93 patients (Table 2). Except for age $(55.0 \pm 10.3$ years vs. $48.0 \pm 12.0$ years, $\mathrm{P}=$ $0.002)$ and menopause status $(68.6 \%$ vs. $43.9 \%, \mathrm{P}=0.015)$, the clinicopathologic features were comparable between the low and high PTH groups. The low PTH group showed higher risk of symptomatic hypocalcemia than the high PTH group (61.0\% vs. $11.8 \%, \mathrm{P}<0.001)$. All patients in the high PTH group experienced symptomatic hypocalcemia within 24 hours of surgery, whereas $44.0 \%$ of patients in low PTH group developed symptom after 24 hours $(\mathrm{P}=0.008)$.

Univariate and multivariate analyses indicated that POD 1 PTH level was the only predictive marker of symptomatic hypocalcemia in all patients (Table 3). The incidence of the symptomatic hypocalcemia was 20.9 times (95\% confidence interval [CI], 6.8-64.5, $\mathrm{P}<0.001$ ) higher in the low PTH group. The development of postoperative symptomatic hypocalcemia was not correlated with clinicopathologic features, combined central neck dissection, number of sacrificed parathyroid glands, or routine supplementation of low-dose calcium. Subgroup analysis in female patients also indicated that POD 1 PTH was the only predictive marker and menopause showed no association with symptomatic hypocalcemia (odds ratio, 2.7; $95 \% \mathrm{CI}, 0.4-16.7, \mathrm{P}=0.281$ ).

\section{DISCUSSION}

Routine supplementation with low-dose calcium $(1,500$ 
Table 2. Clinicopathological features of the low and high PTH groups

\begin{tabular}{|c|c|c|c|}
\hline Characteristic & Low PTH group $(n=41)$ & High PTH group $(n=93)$ & P-value \\
\hline Age $(y r)$ & $55.0 \pm 10.3$ & $48.0 \pm 12.0$ & 0.002 \\
\hline Female sex & $35(85.4)$ & $82(88.2)$ & 0.653 \\
\hline Menopause in female & $24 / 35(68.6)$ & $36 / 82(43.9)$ & 0.015 \\
\hline Combined central LN dissection & $30(73.2)$ & $64(68.8)$ & 0.612 \\
\hline Inadvertent PTG excision & & & 0.427 \\
\hline 1 PTG & $5(12.2)$ & $8(8.6)$ & \\
\hline 2 PTGs & $0(0)$ & $3(3.2)$ & \\
\hline PTG autotransplantation & $2(4.9)$ & $2(2.2)$ & 0.393 \\
\hline \multicolumn{4}{|l|}{ Pathologic features } \\
\hline Tumor size $(\mathrm{cm})$ & $1.3 \pm 1.4$ & $1.1 \pm 0.6$ & 0.289 \\
\hline Minimal extrathyroidal extension & $26(63.4)$ & $57(61.3)$ & 0.815 \\
\hline LN metastasis & $19(46.3)$ & $34(36.6)$ & 0.286 \\
\hline AJCC 7th classification & & & 0.663 \\
\hline T1N0 & $6(14.6)$ & $15(16.1)$ & \\
\hline T1N1a & $5(12.2)$ & $12(12.9)$ & \\
\hline $\mathrm{T} 1 \mathrm{Nx}$ & $3(7.3)$ & $8(8.6)$ & \\
\hline $\mathrm{T} 2 \mathrm{~N} 1 \mathrm{a}$ & $0(0)$ & $1(1.1)$ & \\
\hline T3N0 & $8(19.5)$ & $29(31.2)$ & \\
\hline T3N1a & $14(34.1)$ & $21(22.6)$ & \\
\hline $\mathrm{T} 3 \mathrm{Nx}$ & $5(12.2)$ & $7(7.5)$ & \\
\hline \multicolumn{4}{|l|}{ Postoperative findings } \\
\hline Symptomatic hypocalcemia & $25(61.0)$ & $11(11.8)$ & $<0.001$ \\
\hline Occurred within $24 \mathrm{hr}$ & $14 / 25(56.0)$ & $11 / 11(100)$ & 0.008 \\
\hline IV calcium dosage (mg) & $691.9 \pm 505.2$ & $558.0 \pm 275.9$ & 0.417 \\
\hline Permanent hypocalcemia & $1(2.4)$ & $0(0)$ & 0.131 \\
\hline
\end{tabular}

Values are presented as mean \pm standard deviation or number $(\%)$.

PTH, parathyroid hormone; LN, lymph node; PTG, parathyroid gland; AJCC, American Joint Committee on Cancer; IV, intravenous.

Table 3. Predictive factors for transient hypoparathyroidism in univariate and multivariate analyses

\begin{tabular}{|c|c|c|c|c|}
\hline \multirow{2}{*}{ Covariates } & \multicolumn{2}{|c|}{ Univariate analysis } & \multicolumn{2}{|c|}{ Multivariate analysis } \\
\hline & Odds ratio $(95 \% \mathrm{Cl})$ & P-value & Odds ratio $(95 \% \mathrm{Cl})$ & P-value \\
\hline \multicolumn{5}{|l|}{ Clinical features } \\
\hline Age at surgery & $1.003(0.971-1.035)$ & 0.875 & $0.963(0.922-1.007)$ & 0.095 \\
\hline Male sex & $0.545(0.147-2.022)$ & 0.365 & $0.190(0.033-1.076)$ & 0.061 \\
\hline \multicolumn{5}{|l|}{ Surgical characteristics } \\
\hline Combined CLND & $0.800(0.352-1.816)$ & 0.594 & $0.667(0.194-2.294)$ & 0.520 \\
\hline T stage & Reference (T1) & & Reference (T1) & \\
\hline T stage (T2) & $<0.001$ (0.000-infinite) & $>0.999$ & 1.225 (0.000-infinite) & $>0.999$ \\
\hline T stage (T3) & $1.044(0.471-2.312)$ & 0.915 & $0.995(0.370-2.679)$ & 0.992 \\
\hline N1a stage & $1.319(0.608-2.860)$ & 0.483 & $1.478(0.509-4.292)$ & 0.472 \\
\hline Sacrificed parathyroid glands & Reference (none) & & Reference (none) & \\
\hline 1 Gland sacrificed & $1.194(0.344-4.151)$ & 0.780 & $1.095(0.231-5.194)$ & 0.909 \\
\hline 2 Glands sacrificed & $<0.001$ (0.000-infinite) & 0.999 & $<0.001$ (0.000-infinite) & 0.999 \\
\hline Parathyroid autotransplantation & $2.824(0.383-20.834)$ & 0.309 & $3.508(0.241-51.032)$ & 0.358 \\
\hline POD 1 PTH $<13$ pg/mL & $11.648(4.789-28.327)$ & $<0.001$ & $20.649(6.622-64.388)$ & $<0.001$ \\
\hline Routine calcium supplementation & $1.718(0.793-3.722)$ & 0.170 & $2.453(0.839-7.173)$ & 0.101 \\
\hline
\end{tabular}

$\mathrm{Cl}$, confidence interval; CLND, central lymph node dissection; POD, postoperative day; PTH, parathyroid hormone. 
$\mathrm{mg} /$ day) after thyroidectomy did not reduce the rate of symptomatic hypocalcemia or the need for intravenous calcium in the present study. We also found that POD 1 PTH level < $13 \mathrm{pg} / \mathrm{mL}$ could be a predictive factor for the development of postoperative hypocalcemia. Routine supplementation of lowdose calcium is currently used in many centers, whereas few published reports investigated the efficacy of this low-dose calcium supplementation. To my best knowledge, only Choe et al. [21] reported the efficacy of low-dose calcium and suggested that routine supplementation of low-dose calcium $(1,200$ $\mathrm{mg} /$ day) did not prevent severe symptomatic hypocalcemia requiring intravenous calcium gluconate. Although prophylactic calcium supplementation was cost-effective, not labor-intensive, and expeditious, the optimal dosing is needed for further validation [22].

As low-dose calcium supplementation showed no preventive effect for postoperative hypocalcemia, issues were raised of the patients who could be safely discharged earlier without medication and for whom calcium supplement would be helpful. Over $60 \%$ of patients whose PTH level $<13 \mathrm{pg} /$ $\mathrm{mL}$ suffered from hypocalcemic symptoms, and $44.0 \%$ of symptomatic patients developed symptom after 24 hours. On the contrary, although $11.8 \%$ of patients with POD 1 PTH level over $13-\mathrm{pg} / \mathrm{mL}$ experienced symptomatic hypocalcemia, such patients developed symptom within 24 hours in all cases. Our results indicated that close monitoring of calcium level and appropriate calcium supplementation was beneficial for patients with PTH level $<13 \mathrm{pg} / \mathrm{mL}$. Early discharge can be considered safe for the asymptomatic patients during the first 24 hours, whose PTH level $\geq 13 \mathrm{pg} / \mathrm{mL}$.

In the present study, we demonstrated that POD 1 PTH level $<13 \mathrm{pg} / \mathrm{mL}$ was associated with the development of symptomatic hypocalcemia. The cutoff value of $13 \mathrm{pg} / \mathrm{mL}$ was determined by RPART classification algorithm in R. The statistical base of RPART is described elsewhere [20]. RPART algorithm helped us to calculate the cutoff value, which maximized the statistical separation between the groups [23]. Previous studies reported that postoperative PTH could be the most powerful predictor of hypocalcemia, with a different cutoff value from 9.6 to $23 \mathrm{pg} / \mathrm{mL}$ [24-26]. Most of these studies suggested the cut-off value of $10-15 \mathrm{pg} / \mathrm{mL}$, which was consistent with our results. We demonstrated that POD 1 PTH level of $13 \mathrm{pg} / \mathrm{mL}$ was predictive for symptomatic hypocalcemia, and its incidence was about 20 times higher in patients with $\mathrm{PTH}<13 \mathrm{pg} / \mathrm{mL}$.

We found that postoperative low PTH level $<13 \mathrm{pg} / \mathrm{mL}$ was associated with age and menopause status. Menopause may impair intestinal calcium absorption, which increases the risk of postoperative hypocaclcemia [27,28]. However, as older age might be associated with menopause in women, we investigated the association using multivariate logistic regression model. After adjusting confounders, menopause showed no association with postoperative symptomatic hypocalcemia. Other researchers also indicated that the incidence of transient hypoparathyroidism and PTH levels were comparable between pre-menopausal and postmenopausal women [29]. Khosla et al. [27] further demonstrated that serum PTH level was not associated with menopasusal status. Therefore, menopause might have no effect on the PTH level after surgery.

This study had some limitations. First, most of the previous studies used ionized calcium level less than $4.0 \mathrm{mg} / \mathrm{dL}$ to define hypocalcemia $(1.00 \mathrm{mmol} / \mathrm{L})$. In the present study, we used the American Association of Clinical Endocrinologists and American College of Endocrinology definition of symptomatic hypocalcemia, which requires an ionized calcium concentration below $4.6 \mathrm{mg} / \mathrm{dL}(1.15 \mathrm{mmol} / \mathrm{L})$ associated with hypocalcemic symptoms [18]. This higher calcium concentration cutoff level resulted in a comparatively high proportion of patients with symptomatic hypocalcemia, and thus direct comparison of our study results with others may not be relevant. Second, the results of our study may be affected by the higher percentage of patients who performed combined central LN dissection and parathyroid autotransplantation in the routine calcium group, although there were no statistical differences. Further validation studies in larger populations are warranted.

In conclusion, routine low-dose calcium and vitamin D supplements after total thyroidectomy did not reduce the risk of postoperative hypocalcemia. Patients who may benefit from calcium and/or vitamin D supplementation should be carefully selected.

\section{CONFLICTS OF INTEREST}

No potential conflict of interest relevant to this article was reported.

\section{ACKNOWLEDGEMENTS}

This research was supported by Basic Science Research Program through the National Research Foundation of Korea (NRF) funded by the Ministry of Science \& ICT (2017R1C1B5076977). 
1. Oh CM, Won YJ, Jung KW, Kong HJ, Cho $\mathrm{H}$, Lee JK, et al. Cancer statistics in Korea: incidence, mortality, survival, and prevalence in 2013. Cancer Res Treat 2016;48:436-50.

2. Callender GG, Carling T, Christison-Lagay E, Udelsman R. Surgery for thyroid cancer. Endocrinol Metab Clin North Am 2014:43: 443-58.

3. Bergenfelz A, Jansson S, Kristoffersson A, Martensson H, Reihner E, Wallin G, et al. Complications to thyroid surgery: results as reported in a database from a multicenter audit comprising 3,660 patients. Langenbecks Arch Surg 2008; 393:667-73.

4. Kim JP, Park JJ, Son HY, Kim RB, Kim HY, Woo SH. Effectiveness of an i-PTH measurement in predicting post thyroidectomy hypocalcemia: prospective controlled study. Yonsei Med J 2013;54:637-42.

5. Edafe O, Antakia R, Laskar N, Uttley L, Balasubramanian SP. Systematic review and meta-analysis of predictors of postthyroidectomy hypocalcaemia. Br J Surg 2014:101:307-20

6. Kwon YH, Lee KE, Kwon H, Choi JY, Koo DH, Kim E, et al. Preoperative parathyroid hormone level as a predictive factor for post-thyroidectomy hypoparathyroidism. Korean J Clin Oncol 2013;9:28-32.

7. Lee GH, Ku YH, Kim HI, Lee MC, Kim MJ. Vitamin D level is not a predictor of hypocalcemia after total thyroidectomy. Langenbecks Arch Surg 2015;400:617-22.

8. Yoon JH. Prediction for development of hypocalcemic symptoms and signs after total thyroidectomy. In: Shong YK, editor. Thyroid cancer 2011: proceedings of the first Asian master course of thyroid cancer. Seoul: Korean Thyroid Association; 2011. p. 75-80.

9. Antakia R, Edafe O, Uttley L, Balasubramanian SP. Effectiveness of preventative and other surgical measures on hypocalcemia following bilateral thyroid surgery: a systematic review and metaanalysis. Thyroid 2015;25:95-106.
10. Terris DJ, Snyder S, Carneiro-Pla D, Inabnet WB 3rd, Kandil E, Orloff L, et al. American Thyroid Association statement on outpatient thyroidectomy. Thyroid 2013;23:1193-202.

11. Bellantone R, Lombardi CP, Raffaelli M, Boscherini M, Alesina PF, De Crea C, et al. Is routine supplementation therapy (calcium and vitamin D) useful after total thyroidectomy? Surgery 2002;132:1109-12.

12. Pisaniello D, Parmeggiani D, Piatto A, Avenia N, d'Ajello M, Monacelli M, et al. Which therapy to prevent post-thyroidectomy hypocalcemia? G Chir 2005;26: 357-61.

13. Tartaglia F, Giuliani A, Sgueglia M, Biancari F, Juvonen T, Campana FP. Randomized study on oral administration of calcitriol to prevent symptomatic hypocalcemia after total thyroidectomy. Am J Surg 2005;190:424-9.

14. Landry CS, Grubbs EG, Hernandez M, Hu MI, Hansen MO, Lee JE, et al. Predictable criteria for selective, rather than routine, calcium supplementation following thyroidectomy. Arch Surg 2012;147:338-44.

15. Kurukahvecioglu O, Karamercan A, Akin M, Tezel E, Ege B, Taneri F, et al. Potential benefit of oral calcium/vitamin $\mathrm{D}$ administration for prevention of symptomatic hypocalcemia after total thyroidectomy. Endocr Regul 2007:41:35-9.

16. Heimburger DC, McLAren DS, Shils ME. Clinical manifestations of nutrient deficiencies and toxicities: a resume. In: Shils ME, Shike M, Ross AC, Caballeoro B, editors. Modern nutrition in health and disease. 10 ed. Philadelphia (PA): Lippincott Williams \& Wikins; 2010. p. 597.

17. Delbridge L. "Selective rather than routine": using sound clinical judgment. Arch Surg 2012;147:344.

18. Stack BC Jr, Bimston DN, Bodenner DL, Brett EM, Dralle H, Orloff LA, et al. American association of clinical endocrinologists and American college of endocrinology disease state clinical review: postoperative hypoparathyroidism--de- finitions and management. Endocr Pract 2015;21:674-85.

19. Alhefdhi A, Mazeh H, Chen H. Role of postoperative vitamin $\mathrm{D}$ and/or calcium routine supplementation in preventing hypocalcemia after thyroidectomy: a systematic review and meta-analysis. Oncologist 2013;18:533-42.

20. Venables WN, Ripley BD. Modern applied statistics with S. 4th ed. New York: Springer-Verlag; 2002.

21. Choe JH, Kim WW, Lee SK, Lim HI, Choi JH, Lee JE, et al. Comparison of calcitriol versus cholecalciferol therapy in addition to oral calcium after total thyroidectomy with central neck lymph node dissection: a prospective randomized study. Head Neck 2011;33:1265-71.

22. Orloff LA, Wiseman SM, Bernet VJ, Fahey TJ 3rd, Shaha AR, Shindo ML, et al. American Thyroid Association statement on postoperative hypoparathyroidism: diagnosis, prevention, and management in adults. Thyroid 2018;28:830-41.

23. Kalderstam J, Eden P, Ohlsson M. Finding risk groups by optimizing artificial neural networks on the area under the survival curve using genetic algorithms. PLoS One 2015;10:e0137597.

24. Barczynski M, Cichon S, Konturek A. Which criterion of intraoperative iPTH assay is the most accurate in prediction of true serum calcium levels after thyroid surgery? Langenbecks Arch Surg 2007;392: 693-8.

25. Lang BH, Yih PC, Ng KK. A prospective evaluation of quick intraoperative parathyroid hormone assay at the time of skin closure in predicting clinically relevant hypocalcemia after thyroidectomy. World J Surg 2012;36:1300-6.

26. Islam S, Al Maqbali T, Howe D, Campbell J. Hypocalcaemia following total thyroidectomy: early post-operative parathyroid hormone assay as a risk stratification and management tool. J Laryngol Otol 2014; 128:274-8.

27. Khosla S, Atkinson EJ, Melton LJ 3rd, 
Riggs BL. Effects of age and estrogen status on serum parathyroid hormone levels and biochemical markers of bone turnover in women: a population-based study. J Clin Endocrinol Metab 1997;82:
1522-7.

28. Nordin BE, Need AG, Morris HA, O'Loughlin PD, Horowitz M. Effect of age on calcium absorption in postmenopausal women. Am J Clin Nutr 2004:80:998-1002.
29. Sands NB, Payne RJ, Cote V, Hier MP, Black MJ, Tamilia M. Female gender as a risk factor for transient post-thyroidectomy hypocalcemia. Otolaryngol Head Neck Surg 2011:145:561-4. 